\title{
Early Maternal Withdrawal and Nonverbal Childhood IQ as Precursors for Substance Use Disorder in Young Adulthood: Results of a 20-Year Prospective Study
}

\section{Citation}

Pechtel, Pia, Ashley Woodman, and Karlen Lyons-Ruth. 2012. “Early Maternal Withdrawal and Nonverbal Childhood IQ as Precursors for Substance Use Disorder in Young Adulthood: Results of a 20-Year Prospective Study." International Journal of Cognitive Therapy 5 (3) (September): 316-329. doi:10.1521/ijct.2012.5.3.316.

\section{Published Version}

doi:10.1521/ijct.2012.5.3.316

\section{Permanent link}

http://nrs.harvard.edu/urn-3:HUL.InstRepos:37140321

\section{Terms of Use}

This article was downloaded from Harvard University's DASH repository, and is made available under the terms and conditions applicable to Other Posted Material, as set forth at http:// nrs.harvard.edu/urn-3:HUL.InstRepos:dash.current.terms-of-use\#LAA

\section{Share Your Story}

The Harvard community has made this article openly available.

Please share how this access benefits you. Submit a story.

\section{Accessibility}




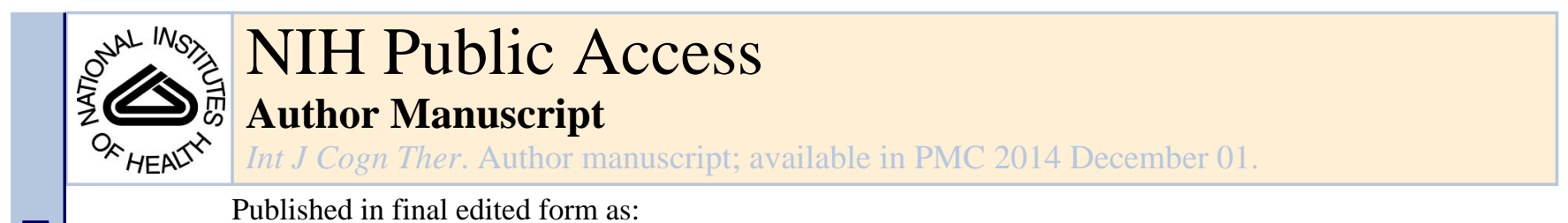

Published in final edited form as:

Int J Cogn Ther. 2012 ; 5(3): 316-329. doi:10.1521/ijct.2012.5.3.316.

\title{
Early Maternal Withdrawal and Nonverbal Childhood IQ as Precursors for Substance Use Disorder in Young Adulthood: Results of a 20-Year Prospective Study
}

\author{
Pia Pechtel, \\ McLean Hospital, Harvard Medical School \\ Ashley Woodman, and \\ Boston College \\ Karlen Lyons-Ruth \\ Cambridge Hospital, Harvard Medical School
}

\section{Abstract}

The relation between early mother-infant interaction and later socio-emotional development has been well established. The present study addresses the more recent interest in the impact of maternal caregiving on cognitive development and their role in decision-making in young adulthood. Using data from a prospective longitudinal study on attachment, prediction from early mother-infant interactions at age 18 months and from verbal and nonverbal cognitive skill at age 5 were examined as predictors of a substance use disorder (abuse/dependence) in young adulthood (age 20) on the Structured Clinical Interview for DSM-IV (SCID). Results reveal that the mother's withdrawal from interaction with the infant at age 18 months, coded using the AMBIANCE coding system (Atypical Maternal Behavior Instrument for Assessment and Classification), was associated with the child's lower nonverbal cognitive scores but not verbal cognitive scores at age 5. In addition, maternal withdrawal at 18 months predicted a clinical diagnosis of substance use disorder (alcohol/cannabis) at age 20. Finally, nonverbal reasoning at age 5 mediated the relationship between early maternal withdrawal and substance use disorder (alcohol/cannabis) in young adulthood. Findings indicate the need for further work examining how early maternal withdrawal affects nonverbal cognitive development by school entry, and how these nonverbal deficits further contribute to maladaptive coping strategies such as substance use by young adulthood.

Quality of maternal caregiving behavior has been widely shown to influence children's social-emotional and cognitive development (Landry, Smith, Swank, Assel, \& Vallet, 2001). For more than two decades, research has demonstrated that maternal sensitivity to infants' needs relates to greater attachment security between mother and infant (Ainsworth, 1979; Bigelow et al., 2010), enhanced capacity for infants' emotion regulation (Conradt \& Ablow, 2010), and increased prosocial, empathic responses (Davidov \& Grusec, 2006). In addition, 
a randomized controlled trial demonstrated that infants whose mothers underwent interventions to improve maternal warmth and responsiveness showed enhancements in social and cognitive development from 6 to 13 months compared to infants whose mothers did not receive the intervention (Landry, Smith, \& Swank, 2006). Thus, early maternal contingent and responsive behavior appears to scaffold development of the child's own skills in the regulation of arousal and negative affect (McElwain \& Booth-LaForce, 2006).

Maternal responsiveness and contingent behavior have also been associated with improved cognitive ability and language development (Beckwith \& Rodning 1996; Eshel, Daelmans, de Mallo, \& Martines, 2006; Field, Guy, \& Umbel, 1985; Landry et al., 2006; Lemelin, Tarabulsy, \& Provost, 2006; Smith, Landry, \& Swank, 2006). In humans, greater maternal sensitivity was related to improved cognitive development at 12 months (Jaffe, Beebe, Feldstein, Crown, \& Jasnow, 2001), 18 months (Murray, Fiori-Crowley, Hooper, \& Cooper, 1996), 36 months (Lemelin et al., 2006), and 5 years (Murray, Hipwell, Hooper, Stein, \& Cooper, 1996), as well as to school performance at age 10 (Smith et al., 2006) and IQ at age 12 (Beckwith, Rodning, \& Cohen, 1992). Degree of maternal sensitivity has also been shown to contribute to early language abilities measured by infants' vocabulary at 12 months (Ruddy \& Bornstein, 1982) and 21 months (Tomasello \& Farrar, 1986), as well as by earlier development of language milestones (Tamis-Lemonda \& Bornstein, 2002; TamisLemonda, Bornstein, \& Baumwell, 2001).

While measures of maternal sensitivity have predicted important positive outcomes, they have not been strong predictors of attachment disorganization in infancy (NICHD ECCRN, 2001; van IJzendoorn, Schuengel, \& Bakermans-Kranenburg, 1999). Instead more detailed assessments of negative maternal behaviors have been needed. One such assessment, the AMBIANCE coding system (Atypical Maternal Behavior Instrument for Assessment and Classification), includes coding criteria for five dimensions of disrupted maternal behavior, including (1) affective communication errors; (2) role confusion; (3) negative-intrusive behavior; (4) disorientation; and (5) withdrawal. Maternal disrupted behavior assessed on the AMBIANCE has shown good validity in relation to both maternal and infant attachment disorganization (Madigan et al., 2006), as well as a range of other maladaptive child outcomes (e.g., Bureau, Easterbrooks, \& Lyons-Ruth, 2009; Dutra, Bureau, Holmes, Lyubchik, \& Lyons-Ruth, 2009; Shi, Bureau, Easterbrooks, Zhao, Lyons-Ruth, 2012). While a number of studies have identified an association between such disrupted parenting styles and oppositional defiant behavior in youth (e.g., van der Molen, Hipwell, Vermeiren, \& Loeber, 2011), very few studies have had the scope to monitor these outcomes into adulthood. For example, retrospective reports support the relationship between lack of parental warmth and adult substance use (Montegomery, Fisk, \& Craig, 2008). However, prospective study designs are critical to further examine this developmental trajectory of early maternal caregiving and adult substance use. In line with social learning theory, deficits in self-regulatory processes are thought to form a functional mechanism that mediates the pathway from dysfunctional parenting to subsequent substance use in young adulthood (Patock-Peckham, Cheong, Balhorn, \& Nagoshi, 2001).

In addition to child behavioral problems, disruptions in the mother-infant attachment relationship have been shown to influence cognitive development (for a review see Lyons- 
Ruth \& Jacobvitz, 2008). In a 10-year longitudinal study of 85 Icelandic children, Jacobsen, Edelstein, and Hofmann (1994) found that children with disorganized attachment patterns at age 7 exhibited a poorer performance on measures of syllogistic reasoning from age 9 to 17 compared to secure and insecure children, even when controlling for potential confounds such as IQ, attention, and self-confidence. Difficulties in nonverbal reasoning, in turn, may contribute to academic problems. Moss and colleagues found that disorganized children demonstrated poorer math performance at ages 5 to 7 and more difficulties in problemsolving tasks at ages 7 to 9, despite adequate overall IQ (Moss, Rousseau, Parent, St.Laurent, \& Saintonge, 1998; Moss \& St.-Laurent, 2001; Moss, St.-Laurent, \& Parent, 1999). In a recent follow-up, the punitive subgroup of disorganized controlling children was evaluated as having poorer academic performance than secure children even when controlling for sex, IQ, and family socioeconomic status (Bureau, Moss, \& St.-Laurent, 2006). Disrupted maternal caregiving and infant disorganization may therefore negatively affect nonverbal reasoning in particular, with further impact on problem solving and school achievement.

Most recently, Pearson and colleagues (2011) reported an association between maternal positive nonverbal responses and children's verbal IQ and nonverbal IQ at age 4. However, they found that this effect was attenuated when including maternal education as well as other covariates likely to impact development (e.g., infant developmental scores at age 6 months, maternal age at delivery, parity, socioeconomic background, gestation at birth, breast feeding). Emphasizing the need to evaluate the specific type of mother-infant interaction associated with cognitive outcomes, Page and colleagues (Page, Wilhelm, Gamble, \& Card, 2010) found that maternal verbal communication, but not overall maternal sensitivity, predicted infant cognitive ability. As verbal communication between the mother and the infant promotes cognitive growth (Page, Wilhelm, Gamble, \& Card, 2010), maternal lack of verbal, affective, and physical availability, as captured in the coding of maternal withdrawal, may contribute to impairment in cognitive development. Findings emphasize the need to consider the specific impact of different types of maternal behavior, as well as to control for other correlated environmental factors. Interestingly, similar to research on early caregiving, childhood IQ has also been linked to substance abuse behaviors in adulthood. For example, in a cohort study of 12,150 children born in Scotland, higher childhood IQ scores at the age of 11 years were associated with lower prevalence of alcohol-related hangovers in middle adulthood (Batty, Deary, \& Macintyre, 2006). Prospective research spanning from early childhood to adulthood will therefore be critical to investigate the relationships between early caregiving, childhood cognitive functioning, and adult substance use.

While promising, research to date has been limited in (a) characterizing the specific types of maternal behavior associated with cognitive and social outcomes, (b) controlling for a range of confounding variables (e.g., demographic risk, maternal IQ, etc.), and (c) monitoring the impact of maternal and cognitive factors into young adulthood. The present study addressed these gaps by examining the impact of a specific type of disrupted early caregiving, maternal withdrawal, on the development of verbal and nonverbal cognitive skills at age 5, as well as on Axis I substance use disorder (SUD) diagnoses assessed using the Structured Clinical 
Interview for DSM-IV (SCID; First, Spitzer, Gibbon, \& Williams, 1996) in young adulthood. Maternal withdrawal on the AMBIANCE assessment is characterized by creating physical distance (e.g., holding infant away from body with stiff arms) and verbal distance (e.g., silent interaction) from the child when reunited after a stressful separation. In validity analyses in infancy, maternal withdrawal has been associated with infant disorganized attachment in lab assessments $(r=.28, p<.005)$ and increased infant crying in home observations ( $r=.25, p<.005$; Lyons-Ruth, Bronfman, \& Parsons, 1999). In all analyses, substance use disorder (SUD) was defined as a diagnoses of either substance abuse or dependence. These were combined to include younger adults who, as a result of their age, did not yet meet criteria for substance dependence but whose abuse suggests a path to eventual dependence. In sum, the present study hypothesizes that: (1) higher levels of maternal withdrawal in the mother-child interaction at age 18 months would be related to lower verbal and nonverbal cognitive skills in early childhood (age 5); (2) young adults with a SUD diagnosis would have lower verbal and nonverbal cognitive skills at age 5 than young adults without such diagnosis; and (3) the relation between maternal caregiving in infancy and SUD diagnosis in young adulthood would be mediated by the effect of early maternal care on later child cognitive skills.

\section{METHOD}

\section{Participants}

Participants were part of an initial cohort of 76 families recruited during the first 18 months of the child's life to study the impact of social risk factors on child development. Families were at or below $200 \%$ of federal poverty level at study entry. Among the initial 76 families, 56 families were followed up in young adulthood, yielding a retention rate of $74 \%$. Fourteen percent (11) could not be relocated; 9\% (7) refused; and 3\% (2) lived overseas. Attrition was not related to any of the infancy or childhood assessments in the study-effect sizes ( $\varphi$ or $\eta)$ $=-.14$ through .13 - and was associated with only one of eight socioeconomic indicessingle parenthood: $\mathrm{x}^{2}(1, N=76)=8.66, \varphi=.34, p=.01$. Follow-up of this finding indicated that $68 \%$ of those followed up had a partner in the home in infancy, compared to $30 \%$ of those not returning for the young adult follow-up assessment.

The present analysis included participants with data on both the quality of maternal care at 18 months and the psychiatric diagnostic interview at age $20(N=35 ; 15$ female, 20 male). For these participants, the mean age of the child at the time of the maternal interaction assessment was 18.5 months ( $S D=.92$ months), 5.0 years for the cognitive assessment ( $S D$ $=4.78)$, and 19.5 years for the psychiatric interview $(S D=1.42)$. Overall, the subsample used in the current study did not differ from the larger sample in terms demographic risk in childhood, $t(74)=.461 p=.646$, and key variables of maternal withdrawal, $t(60)=-.686, p$ $=.496$, cognitive assessment in childhood, $t(62)=-1.41, p=.165$, and diagnostic assessment of SUD for alcohol and cannabis, $t(44)=-1.32, p=.192$, or other drugs, $t(44)=$ $1.01, p=.317$, in young adulthood. 


\section{Procedure}

Disrupted Mother-Infant Interaction (18 Months)—Disrupted maternal interaction was coded in the Strange Situation Procedure (Ainsworth, Blehar, Waters, \& Wall, 1978) using the Atypical Maternal Behavior Instrument for Assessment and Classification (AMBIANCE) (Lyons-Ruth et al., 1999). Coders were naive to all other data. Maternal withdrawal is one of five classes of disrupted maternal communication coded for frequency and severity as part of the AMBIANCE assessment, including: affective communication errors, role confusion, negative-intrusive behavior, disorientation, and withdrawal. Fifteen randomly selected tapes from the current sample were coded by two coders to assess reliability. The reliability intraclass correlations were as follows ( $n=15)$ : Affective Communication Errors, $r_{\mathrm{i}}=.75$; Role Confusion, $r_{\mathrm{i}}=.76$; Negative-Intrusive Behavior, $r_{\mathrm{i}}=$. 84; Disorientation, $r_{\mathrm{i}}=.73$; Withdrawal, $r_{\mathrm{i}}=.73$. Validity of the AMBIANCE scale in relation to infant attachment disorganization has shown a meta-analytic effect size of $.35, p$ $<.001$ ( $N=384$ and 203; Madigan et al., 2006); test-retest data for the AMBIANCE for periods ranging from 8 months to 5 years yielded a meta-analytic stability coefficient of .56 , $p<.001(N=203)$.

Based on previous work, maternal withdrawal was the dimension of interest in this study. Maternal withdrawal was characterized by creating physical distance from the infant (e.g., holding infant away with stiff arms) or creating communicative distance from the infant (e.g., not greeting infant after separation, silent interactions). Maternal withdrawal coded in the laboratory was significantly negatively correlated with maternal involvement coded in a 40-minute observation in the home ( $r=-.29, p<.02, N=64$; Lyons-Ruth et al., 1999).

Cognitive Performance in Early Childhood (Age 5)—Cognitive performance was assessed using the Wechsler Preschool and Primary Scales of Intelligence (WPPSI; Wechsler, 1967). The Information (verbal) and Mazes (nonverbal) subtests of the WPPSI were administered to the children as estimates of verbal and nonverbal IQ scores. The Information subtest was chosen because it has the highest correlation of all the verbal subtests both with the full-scale IQ score $(r=.70)$ and with the overall verbal IQ score $(r=$. 73). While the various nonverbal subtests have only moderate correlations with overall nonverbal IQ and full-scale IQ scores, the Mazes subtest is the most reliable of the nonverbal subtests and demonstrates acceptable correlations with performance (nonverbal) IQ score $(r=.57)$ and full-scale IQ score $(r=.54)$. Participants' scores on the Information subtest of the WPPSI at age 5 demonstrated a significant positive correlation with verbal IQ as measured by the Similarities subtest of the Wechsler Adult Intelligence Scale (WAIS; Wechsler, 1955) at age $20(r=.44, p<.01)$. Similarly, scores on the Mazes subtest at age 5 correlated with scores on the nonverbal Matrix subtest of the WAIS administered at age 20 $(r=.50, p<.01)$.

Substance Use Disorders (Age 20)—Young adults' substance use disorders were assessed using the Structured Clinical Interview for DSM-IV (SCID) for the Diagnostic and Statistical Manual of Mental Disorders (DSM-IV) Axis I, administered in the laboratory by trained clinicians (American Psychiatric Association, 2000; First et al., 1996). The SCID has demonstrated excellent inter-rater reliability with kappa values of .94 for alcohol abuse and 
dependence and .96 for cannabis abuse and dependence (Martin, Pollock, Oscar, Bukstein, \& Lynch, 2000).

Maternal IQ-To provide an estimate of maternal IQ, the Similarities subscale of the WAIS was administered when the child was 18 months old. In the WAIS standardization sample, this subscale has a Cronbach's reliability coefficient of .85 and correlations of .79 and .83 with Full-Scale IQ and Verbal IQ, respectively (Wechsler, 1955).

Demographic Risk Index-A cumulative demographic risk index was calculated by summing the presence of the following five factors: (a) single parenthood, (b) family income of less than $\$ 40,000$, (c) more than 2 children under age 6 , (d) no maternal education beyond high school, and (e) mother under age 20 at birth of first child.

\section{Analysis}

Bivariate correlations and independent samples $t$-tests (two-tailed) examined the relations between early maternal withdrawal at age 18 months, verbal and nonverbal IQ at age 5 (Hypothesis 1), and Axis I substance use disorders on the SCID at age 20 (Hypothesis 2). Logistic regression was used to identify predictors of SUD diagnosis at age 20. In order to test the unique contributions of maternal withdrawal and verbal and nonverbal IQ on young adults' SUD diagnoses, predictor variables were entered in the following blocks: (1) Demographic risk, maternal IQ, child gender, (2) maternal withdrawal, (3) child verbal and nonverbal IQ. Finally, Preacher and Hayes's (2008) INDIRECT macro for SPSS software 19 was used to estimate the total, direct, and single-step indirect effects of maternal withdrawal on adult SUD outcomes (age 20) through IQ (age 5; Hypothesis 3). Bootstrap confidence intervals were generated for the indirect effect of maternal withdrawal on SUD through child IQ and estimated as the product of the path from the independent variable to the dependent variable and the path from the proposed mediator to the outcome (see Preacher \& Hayes, 2008). If the upper and lower bounds of these confidence intervals do not contain zero, the indirect effect is significant at the level specified. Testing mediation as the product of the coefficients using bootstrap confidence intervals is the preferred method of analysis for smaller samples because the Sobel test makes assumptions about the shape of the sampling distribution of the indirect effect (Dearing \& Hamilton, 2006). INDIRECT supports estimation of models with a binary dependent variable. The direct effect, total effects, and the path from the proposed mediator to the outcome were estimated using logistic regression. The path from the independent variable to the proposed mediator was estimated using ordinary least squares regression. The bootstrap confidence intervals for the indirect effect accounted for differences in the scaling of the pathways.

Multiple Imputation Procedures for Missing Data-Following the recommendations of Schafer and Graham (2002), multiple imputation procedures were employed to estimate missing data. Missing data were imputed using the Markov Chain Monte Carlo procedure in SPSS (Gilks, Richardson, \& Spiegelhalter, 1996). Initially, the sample was selected based on completed data on the AMBIANCE, SCID, and relevant covariates (gender, demographic risk, maternal IQ). This yielded only $5.2 \%$ of missing values on the remaining variables. Consistent with the literature, a single imputation was therefore deemed sufficient due to the 
nominal amount of missing data (Widaman, 2006). Results using the imputed data set replicated results using the original dataset.

\section{RESULTS}

As seen in Table 1, higher levels of maternal withdrawal in infancy were associated with lower levels of nonverbal IQ (Mazes subtest; $r=-.35, p<.05$ ) but not verbal IQ (Information subtest; $r=-.01, p>.05$ ). Thus, the first hypothesis of a relation between early maternal withdrawal and later cognitive skills was confirmed for non-verbal skills only.

Moreover, $37 \%$ of the sample qualified for a diagnosis of SUD for alcohol or cannabis $(N=$ 13), and high maternal withdrawal was also associated with SUD diagnosis for cannabis/ alcohol $(r=.36, p<.05)$. Although SUD involving illicit substances other than alcohol and cannabis was also associated with higher maternal withdrawal $(r=.42, p<.05)$, only a small number of participants qualified for a SUD involving these substances $(14.3 \%, N=5)$ so these results were not further followed up. Critically, SUD for alcohol or cannabis was associated with lower nonverbal IQ but not verbal IQ at age 5 (Table 1). Gender, family demographic risk, and maternal IQ were not related to any of the variables of interest. Given the interrelations found among maternal withdrawal, lowered nonverbal cognitive skills and increased substance abuse, nonverbal skill was further evaluated as a potential mediator linking early withdrawal and later substance abuse.

Participants with a diagnosis of SUD (alcohol, cannabis) showed higher levels of maternal withdrawal $(M=4.46 ; S D=3.07)$ than participants without a diagnosis $(M=2.41 ; S D=$ $2.42), t(33)=-2.19, p<.05$. Participants with a SUD diagnosis had lower nonverbal IQ skills $(M=6.54, S D=2.33)$, but not lower verbal IQ, than young adults without such a diagnosis $(M=9.47, S D=2.62), t(33)=3.23, p<.01$. Specifically, young adults with a SUD diagnosis experienced higher levels of maternal withdrawal and demonstrated lower levels of nonverbal IQ. These findings support the second hypothesis regarding the relationship between nonverbal IQ at age 5 and SUD at age 20, but not between verbal IQ and SUD.

Table 2 summarizes the results of the logistic regression model predicting SUD (alcohol/ cannabis) in young adulthood. Control variables were entered first, followed by maternal withdrawal as Block 2, and child verbal and nonverbal IQ as Block 3. Higher levels of maternal withdrawal at 18 months predicted a higher likelihood of having a SUD diagnosis at age 20, after controlling for demographic risk, maternal IQ, and child gender. Lower early childhood nonverbal IQ, but not verbal IQ, predicted additional variation in SUD (alcohol, cannabis) diagnosis later in life, beyond that associated with maternal withdrawal. Maternal withdrawal became a nonsignificant predictor of SUD after child verbal and nonverbal IQ were included in the model (Table 2, Final Block).

Findings from the logistic regression model suggest that child nonverbal IQ, but not verbal IQ, may mediate the relationship between maternal withdrawal and SUD diagnosis. To test this final mediation hypothesis, the INDIRECT macro used maternal withdrawal as the independent variable, child nonverbal IQ as the proposed mediator, and SUD diagnosis as 
the dependent variable with verbal IQ as a covariate. Demographic risk, maternal IQ, and child gender were not included as covariates in the mediation analysis given their lack of association with a SUD diagnosis in the independent samples $t$-test (Table 1) and logistic regression (Table 2) analyses.

As a prerequisite to the mediation analysis, the bivariate associations between (a) maternal withdrawal and child nonverbal IQ, (b) child nonverbal IQ and SUD diagnosis, and (c) maternal withdrawal and SUD diagnosis were confirmed (Table 1). In the mediation analysis, greater maternal withdrawal was found to predict lower child nonverbal IQ (a path; $\beta=-.35, p=.04$ ). Child nonverbal IQ had a direct effect on SUD diagnosis (b path), with lower levels of nonverbal IQ predicting a greater likelihood of having a SUD diagnosis $(\beta=$ $-.51, p=.02$ ). A significant total effect of maternal withdrawal on SUD diagnosis (c path) was found $(\beta=.28, p=.05)$. The direct effect of maternal withdrawal on SUD, controlling for child nonverbal IQ (c' path), was nonsignificant ( $\beta=.21, p=.18$ ) consistent with the mediation hypothesis. The partial effect of child verbal IQ on SUD diagnosis was nonsignificant $(\beta=.21, p=.26)$. Table 3 shows that the indirect effect of maternal withdrawal on SUD diagnosis through child nonverbal IQ was supported. The point estimate of the cross product of the coefficients $\left(a^{*} \mathrm{~b}\right)$ was statistically significant at the $95 \%$ level.

To illustrate the mediating role of child nonverbal IQ, coefficients for each pathway were made comparable by multiplying each coefficient by the standard deviation of the predictor variable divided by the standard deviation of the outcome variable for each pathway: a * $\mathrm{SD}(\mathrm{X}) / \mathrm{SD}(\mathrm{M}), \mathrm{b} * \mathrm{SD}(\mathrm{M}) / \mathrm{SD}(\mathrm{Y})$, etc. This step was necessary for interpretation since some pathways were estimated using logistic regression while others were estimated using ordinary least squares regression. These coefficients are presented in Figure 1.

\section{DISCUSSION}

There is increasing interest in how cognitive deficits may contribute to psychiatric disorders. The current study used a 20-year prospective design to investigate potential cognitive contributors to pathways from early disrupted care to later Axis I psychiatric disorders at age 20. Findings revealed first that high levels of maternal withdrawal in infancy were associated with increased rates of SUD diagnoses for alcohol and cannabis in young adulthood. SUD of these common drugs in young adulthood was in turn related to nonverbal IQ deficits at school entry. Early maternal withdrawal was also related to deficits in nonverbal performance, but not verbal performance by school entry. Finally, this relation between early maternal withdrawal and SUD (cannabis, alcohol) was fully mediated by nonverbal cognitive performance at age 5 .

Our findings add to existing research emphasizing the critical impact of maternal caregiving on the cognitive development of the child (Moss et al., 1998, 1999; Moss \& St.-Laurent, 2001; Page et al., 2010). The present study confirmed an association between maternal behavior and the child's cognitive performance at age 5, while controlling for several important potential confounds including maternal IQ, maternal education, single parenthood, family income of less than $\$ 40,000$, family with more than two children under 6 years, and maternal age at birth of first child. However, early maternal withdrawal was only related to 
lower nonverbal skills, but not verbal skills. Other longitudinal research has also found effects of maternal disrupted caregiving on nonverbal skills (Jacobsen et al., 1994; Moss et al., 1998, 1999; Moss \& St.-Laurent, 2001; Sroufe, Egeland, Carlson, \& Collins, 2005), including math skills and visual logic problems (Raven's matrices). Moreover, mothers of children with nonverbal learning disorders but not other types of learning disorders reported higher levels of dysfunctional interaction with their children (Antshel \& Joseph, 2006). Although few studies have been conducted to date, findings emphasize the need for research to distinguish between verbal and nonverbal components of cognitive performance when examining the impact of early caregiving behavior on children's cognitive development.

It can be speculated that the lack of consistent verbal, affective, and physical contact by the mother during the first 18 months creates a highly stressful experience for the child that can interfere with the structural and functional development of brain regions undergoing maturation at the time (Teicher, Samson, Polcari, \& McGreenery, 2006; Teicher, Tomoda, $\&$ Andersen, 2006). For example, essential functions that are needed shortly after birth, such as primary sensorimotor function but also emotion reactivity (e.g., amygdala) and nonverbal processing (e.g., inferior frontal gyrus) may therefore be more vulnerable to the effects of early stress than language-based reasoning or higher executive levels of cognitive functioning which are thought to develop later in childhood (e.g., gray matter volume of the dorsolateral prefrontal cortex peaks at age 10.5 years; Pechtel \& Pizzagalli, 2011). Deficits in nonverbal reasoning may then contribute to difficulties in social cognition and higher negative arousal in social contexts, contributing to increased difficulties in emotion regulation.

However, after age 3 , children of withdrawn mothers are more likely to take on a caregiving role toward the parent and compensate for the mother's lack of communication (Bureau et al., 2009). Observationally, children who take on this caregiving role often seem somewhat precocious in their verbal fluency. Potentially, this could explain why verbal cognitive performance was not impaired among children of withdrawing mothers. More work is clearly needed to examine why verbal skills are not related to maternal withdrawal to the same extent as nonverbal skills.

Deficits in cognitive development in early childhood have been associated with more frequent engagement in maladaptive behavior in adulthood. For example, Batty and colleagues (2006) demonstrated that higher childhood IQ scores at the age of 11 years were associated with lower prevalence of alcohol-related hangovers in middle adulthood in a cohort study of 12,150 children. However, in the Dunedin longitudinal study, overall childhood IQ was not related to increased risk of drug or alcohol abuse in adulthood at age 32 (Koenen et al., 2009). This difference in results may stem from using an overall measure of IQ, however. In the present study, lower nonverbal IQ was associated with higher use of substances, and in particular, higher use of more socially accepted drugs like alcohol and cannabis. Yet, verbal performance was not related to any type of SUD.

Substance abuse has been shown to form an effective but maladaptive coping strategy to diminish elevated levels of arousal and distress following early life adversity (Pechtel, Evans, \& Podd, 2011). For example, in a twin study, child sexual abuse has been linked to a 
2.7-fold risk for alcohol abuse and dependence and 6.6-fold risk for abuse of other substances (Kendler et al., 2000). Interestingly, in the present study, higher prevalence for alcohol and cannabis SUD were noted compared to SUD involving other illicit drugs. As the nature and accessibility of alcohol and cannabis are very different from other classes of drugs, future studies are encouraged to investigate the specific link between dysfunctional caregiving and alcohol and cannabis abuse. It would be of interest to examine whether alcohol and cannabis constitute a more socially accepted and readily available means of seeking relief from emotional distress following dysfunctional caregiving.

In light of present findings, it may be speculated that high stress caused by maternal withdrawal in the first 18 months of life may impair brain regions undergoing critical development in this early period and which, during this early life stage, play a key role in affective and nonverbal processing. We speculate that such deficits may contribute to difficulties in social understanding and emotion self-regulation and that alcohol and cannabis may serve a compensatory function to relieve heightened distress and arousal in the absence of adaptive regulatory coping skills. Further work is needed to examine the contribution of early maternal withdrawal to the development of non-verbal neuropsychological deficits and its relation to impaired self-regulation.

The current study had a number of limitations that should be addressed by future work. First, given the small sample size of the present study, these links among maternal care, nonverbal skill, and SUD in adulthood will need to be confirmed by future research. Unlike the present study, larger samples would also be able to account for the comorbidity of SUD with other diagnoses. Although sample size is a major limitation, the present study aimed to understand the pathway from early life interaction to adult behavior following participants over a period of 20 years. We selected conservative statistical approaches (e.g., minimized imputation for missing data, bootstrapping mediation models) to avoid overestimation of effects. In addition, although we selected a standardized test of cognitive performance and subtests were selected to provide the strongest estimates of overall verbal and nonverbal IQ, participants only completed two subtests, one verbal and one nonverbal, rather than the complete WPPSI test battery. Thus, future work examining the potential yield of more indepth assessments of nonverbal cognitive function, in particular, is needed.

\section{CONCLUSION}

The present study investigated the implications of maternal withdrawal during the child's infancy for the development of verbal and nonverbal IQ in early childhood (age 5) and for the emergence of SUD diagnoses in young adulthood (age 20). Results indicated that maternal withdrawal in infancy was associated with the child's lower nonverbal reasoning skills by school entry but not lower verbal reasoning skills. In addition, maternal withdrawal in infancy predicted increased risk for SUD (alcohol, cannabis) in young adulthood. Further, nonverbal reasoning skills fully mediated the relationship between maternal withdrawal and later SUD diagnosis (alcohol, cannabis). Mother's withdrawn behavior at an early sensitive period of neurodevelopment may impair the child's nonverbal reasoning skills and lead to increased levels of negative arousal and difficulties in self-regulation. SUD, in turn, may 
function as an effective but maladaptive coping strategy to diminish negative affect and selfregulatory difficulties associated with nonverbal cognitive deficits.

\section{Acknowledgments}

P. Pechtel and A. Woodman did not receive external funding during the preparation of this article. Collection of the data reported on here was supported by grants R01 MH35660 and R01 MH62030 from the National Institute of Mental Health and by a Milton Fund Grant from Harvard University to K. Lyons-Ruth.

\section{REFERENCES}

Ainsworth MD. Infant-mother attachment. American Psychologist. 1979; 34:932-937. [PubMed: 517843]

Ainsworth, MD.; Blehar, MC.; Waters, E.; Wall, S. Patterns of attachment: A psychological study of the strange situation. England: Erlbaum; Oxford: 1978.

American Psychiatric Association. Diagnostic and statistical manual of mental disorders. 4th ed.. Author; Washington, DC: 2000. text revision

Antshel KM, Joseph G-R. Maternal stress in nonverbal learning disorder: A comparison with reading disorder. Journal of Learning Disabilities. 2006; 39:194-205. [PubMed: 16724792]

Batty GD, Deary IJ, Macintyre S. Childhood IQ and life course socioeconomic position in relation to alcohol induced hangovers in adulthood: The Aberdeen children of the 1950s study. Journal of Epidemiology and Community Health. 2006; 60:872-874. [PubMed: 16973534]

Beckwith L, Rodning C. Dyadic processes between mothers and preterm infants: Development at ages 2 to 5 years. Infant Mental Health Journal. 1996; 17:322-333.

Beckwith L, Rodning C, Cohen S. Preterm children at early adolescence and continuity and discontinuity in maternal responsiveness from infancy. Child Development. 1992; 20:283-296.

Bigelow AE, MacLean K, Proctor J, Myatt T, Gillis R, Power M. Maternal sensitivity throughout infancy: Continuity and relation to attachment security. Infant Behavior and Development. 2010; 33:50-60. [PubMed: 20004022]

Bureau J-F, Easterbrooks M-A, Lyons-Ruth K. Attachment disorganization and controlling behavior in middle childhood: Maternal and child precursors and correlates. Attachment and Human Development. 2009; 11:265-284. [PubMed: 19455454]

Bureau, J-F.; Moss, E.; St.-Laurent, D. The roles of attachment and individual and familial processes in the prediction of academic and cognitive functioning. F. Lamb-Parker, Attachment, adult-child relationships, and affect regulation: Contributions to children's later cognitive, social and behavioral competence; Symposium conducted at the Head Start Eighth National Research Conference; Washington, DC. 2006, June;

Conradt E, Ablow J. Infant physiological response to the still-face paradigm: Contributions of maternal sensitivity and infants' early regulatory behavior. Infant Behavior and Development. 2010; 33:251-265. [PubMed: 20207419]

Davidov M, Grusec JE. Untangling the links of parental responsiveness to distress and warmth to child outcomes. Child Development. 2006; 77:44-58. [PubMed: 16460524]

Dearing E, Hamilton LC. Contemporary approaches and classic advice for analyzing mediating and moderating variables. Monographs of the Society for Research in Child Development. 2006; 71:88-104.

Dutra L, Bureau JF, Lyubchnik A, Lyons-Ruth K. Quality of early care and childhood trauma: A prospective study of developmental pathways to dissociation. Journal of Nervous and Mental Disease. 2009; 197:383-390. [PubMed: 19525736]

Eshel N, Daelmans B, de Mello MC, Martines J. Responsive parenting: Interventions and outcome. Bulleting of the World Health Organization. 2006; 84:991-998.

Field T, Guy L, Umbel V. Infants' responses to mothers' imitative behaviors. Infant Mental Health Journal. 1985; 6:40-44.

First, MB.; Spitzer, RL.; Gibbon, M.; Williams, JBW. Structured Clinical Interview for DSM-IV Axis I Disorders, Clinician Version (SCID-CV). American Psychiatric Press; Washington, DC: 1996. 
Gilks, WR.; Richardson, S.; Spiegelhalter, DJ., editors. Markov Chain Monte Carlo in Practice. Chapman \& Hall; London: 1996.

Jacobsen T, Edelstein W, Hofmann V. A longitudinal study of the relation between representation of attachment in childhood and cognitive functioning in childhood and adolescence. Developmental Psychology. 1994; 30:112-124.

Jaffe J, Beebe B, Feldstein S, Crown CL, Jasnow MD. Rhythms of dialogue in infancy: Coordinated timing in development. Monographs of the Society for Research in Child Development. 2001; 66:i-132. [PubMed: 11428150]

Kendler KS, Bulik CM, Silberg J, Hettema JM, Myers J, Prescott CA. Childhood sexual abuse and adult psychiatric and substance use disorders in women: An epidemiological and cotwin control analysis. Archives of General Psychiatry. 2000; 57:953-959. [PubMed: 11015813]

Koenen K, Moffit TE, Roberts AL, Martin LT, Kubzansky L., Harrington, H. Poulton R, Caspi A. Childhood IQ and adult mental disorders: A test of the cognitive reserve hypothesis. American Journal of Psychiatry. 2009; 166:50-57. [PubMed: 19047325]

Landry SH, Smith KE, Swank PR. Responsive parenting: Establishing early foundations for social, communication, and independent problem-solving skills. Developmental Psychology. 2006; 42:627-642. [PubMed: 16802896]

Landry SH, Smith KE, Swank PR, Assel MA, Vellet S. Does early responsive parenting have a special importance for children's development or is consistency across early childhood necessary? Developmental Psychology. 2001; 37:387-403. [PubMed: 11370914]

Lemelin JP, Tarabulsy GM, Provost M. Predicting preschool cognitive development from infant temperament, maternal sensitivity, and psychosocial risk. Merrill-Palmer Quarterly. 2006; 52:779_ 804.

Lyons-Ruth K, Bronfman E, Parsons E. Maternal frightened, frightening, or atypical behavior and disorganized infant attachment patterns. Monographs of the Society for Research in Child Development. 1999; 64:67-96. [PubMed: 10597543]

Lyons-Ruth, K.; Bureau, J-F.; Holmes, B.; East-erbrooks, MA.; Hennighausen, K. Borderline features and suicidality/self-injury: Prospective and concurrent relationship correlates from infancy to young adulthood. in pressManuscript submitted for publication

Lyons-Ruth, K.; Jacobvitz, D. Attachment disorganization: Genetic factors, parenting contexts, and developmental transformation from infancy to adulthood. In: Cassidy, J.; Shaver, PR., editors. Handbook of attachment: Theory, research, and clinical applications. 2nd ed.. Guilford; New York: 2008. p. 666-697.

Madigan S, Bakermans-Kranenburg MJ, Van Ijzendoorn MH, Moran G, Pederson DR, Benoit D. Unresolved states of mind, anomalous parental behavior, and disorganized attachment: A review and meta-analysis of a transmission gap. Attachment \& Human Development. 2006; 8:89-111. [PubMed: 16818417]

Martin CS, Pollock NK, Bukstein OG, Lynch KG. Erratum to "Inter-rater reliability of the SCID alcohol and substance use disorders section among adolescents": [Drug and Alcohol Dependence, 57, 173-176]. Drug and Alcohol Dependence. 2000; 60:323. [PubMed: 11053769]

McElwain NL, Booth-LaForce C. Maternal sensitivity to infant distress and nondistress as predictors of infant-mother attachment security. Journal of Family Psychology. 2006; 20:247-255. [PubMed: 16756400]

Montgomery C, Fisk JE, Craig L. The effects of perceived parenting style on the propensity for illicit drug use: The importance of parental warmth and control. Drug and Alcohol Review. 2008; 27:640-649. [PubMed: 18821098]

Moss E, Rousseau D, Parent S, St.-Laurent D, Saintonge J. Correlates of attachment at school age: Maternal reported stress, mother-child interaction, and behavior problems. Child Development. 1998; 69:1390-1405. [PubMed: 9839423]

Moss E, St.-Laurent D. Attachment at school age and academic performance. Developmental Psychology. 2001; 37:863-874. [PubMed: 11699759]

Moss, E.; St.-Laurent, D.; Parent, S. Disorganized attachment and developmental risk at school age. In: Solomon, J.; George, C., editors. Attachment disorganization. Guilford; New York: 1999. p. 160-187. 
Murray L, Fiori-Cowley A, Hooper R, Cooper P. The impact of postnatal depression and associated adversity on early mother-infant interactions and later infant outcome. Child Development. 1996; 67:2512-2526. [PubMed: 9022253]

Murray L, Hipwell A, Hooper R, Stein A, Cooper P. The cognitive development of 5-year-old children of postnatally depressed mothers. Journal of Child Psychology and Psychiatry. 1996; 37:927-935. [PubMed: 9119940]

NICHD Early Child Care Research Network. Child-care and family predictors of preschool attachment and stability from infancy. Developmental Psychology. 2001; 37:847-862. [PubMed: 11699758]

Page M, Wilhelm MS, Gamble WC, Card NA. A comparison of maternal sensitivity and verbal stimulation as unique predictors of infant social-emotional and cognitive development. Infant Behavior and Development. 2010; 33:101-110. [PubMed: 20089309]

Patock-Peckham JA, Cheong J, Balhorn ME, Nagoshi CT. A social learning perspective: A model of parenting styles, self-regulation, perceived drinking control, and alcohol use and problems. Alcoholism: Clinical and Experimental Research. 2001; 25:1284-1292.

Pearson RM, Heron J, Melotti R, Joinson C, Stein A, Ramchandani PG, et al. The association between observed nonverbal maternal responses at 12 months and later infant development at 18 months and IQ at 4 years: A longitudinal study. Infant Behavior and Development. 2011; 34:525-533. [PubMed: 21840603]

Pechtel P, Evans IM, Podd JV. Conceptualization of the complex outcomes of sexual abuse: A signal detection analysis. Journal of Child Sexual Abuse. 2011; 20:677-694. [PubMed: 22126110]

Pechtel P, Pizzagalli D. Effects of early life stress on cognitive and affective function: An integrated review of human literature. Psychopharmacology. 2011; 214:55-70. [PubMed: 20865251]

Preacher KJ, Hayes AF. Asymptotic and resampling strategies for assessing and comparing indirect effects in multiple mediator models. Behavior Research Methods. 2008; 40:879-891. [PubMed: 18697684]

Ruddy MG, Bornstein MH. Cognitive correlates of infant attention and maternal stimulation over the first year of life. Child Development. 1982; 53:183-188. [PubMed: 7060421]

Schafer JL, Graham JW. Missing data: Our view of the state of the art. Psychological Methods. 2002; 7:147-177. [PubMed: 12090408]

Shi Z, Bureau JF, Easterbrooks MA, Zhao X, Lyons-Ruth K. Childhood maltreatment and prospectively observed quality of early care as predictors of anti-social personality disorder features. Infant Mental Health Journal. 2012; 33:55-69. [PubMed: 22754051]

Smith KE, Landry SH, Swank PR. The role of early maternal responsiveness in supporting schoolaged cognitive development for children who vary in birth status. Pediatrics. 2006; 117:16081617. [PubMed: 16651314]

Sroufe, LA.; Egeland, B.; Carlson, E.; Collins, WA. The development of the person: The Minnesota study of risk and adaptation from birth to adulthood. Guilford; New York: 2005.

Tamis-Lemonda CS, Bornstein MH. Maternal responsiveness and early language acquisition. Advances in Child Development and Behavior. 2002; 29:89-127. [PubMed: 11957576]

Tamis-Lemonda CS, Bornstein MH, Baum-well L. Maternal responsiveness and children's achievement of language milestones. Child Development. 2001; 72:748-767. [PubMed: 11405580]

Teicher MH, Samson JA, Polcari A, McGreenery CE. Sticks, stones, and hurtful words: Relative effects of various forms of childhood maltreatment. American Journal of Psychiatry. 2006; 163:993-1000. [PubMed: 16741199]

Teicher MH, Tomoda A, Andersen S. Neurobiological consequences of early stress and childhood maltreatment: Are results from human and animal studies comparable? Annals of the New York Academy of Sciences. 2006; 1071:313-323. [PubMed: 16891580]

Tomasello M, Farrar MJ. Joint attention and early language. Child Development. 1986; 57:1454-1463. [PubMed: 3802971]

van der Molen E, Hipwell AE, Vermeiren R, Loeber R. Maternal characteristics predicting young girls' disruptive behavior. Journal of Clinical Child and Adolescent Psychology. 2011; 40:179190. [PubMed: 21391016] 
van IJzendoorn MH, Schuengel C, Baker-mans-Kranenburg MJ. Disorganized attachment in early childhood: A meta-analysis of precursors, concomitants, and sequelae. Development and Psychopathology. 1999; 11:225-249. [PubMed: 16506532]

Wechsler, D. Manual for the Wechsler Adult Intelligence Scale (WAIS). Psychological Corporation; Oxford, England: 1955.

Wechsler, D. Manual for the Wechsler Pre-school and Primary Scale (WPPS). Psychological Corporation; Oxford, England: 1967.

Widaman KF. Missing data: What to do with or without them. Monographs for the Society for Research in Child Development. 2006; 71:1540-5834. 


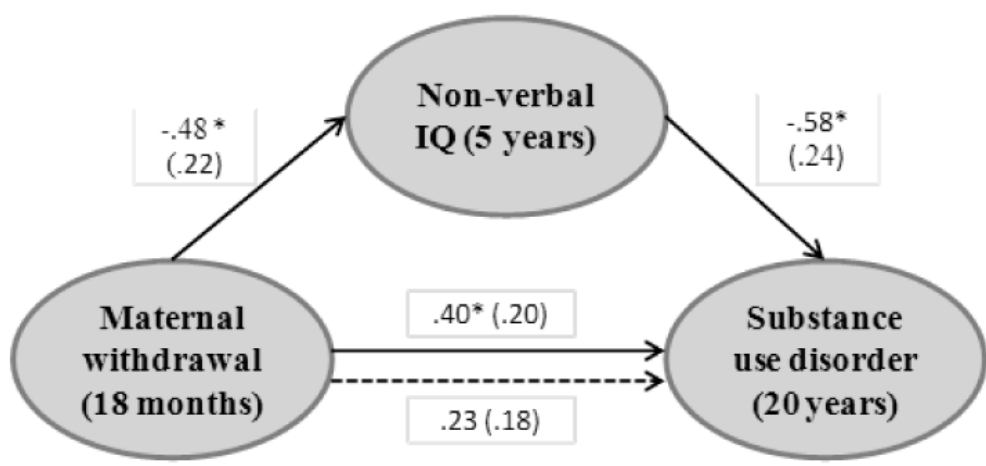

$* p<.05$

FIGURE 1.

Child Nonverbal IQ as a Mediator of the Effects of Maternal Withdrawal on Substance Use Disorder (SUD) Diagnosis (Alcohol/Cannabis) 


\section{Table 1}

Strength of Association among Independent Variables $(N=35)$

\begin{tabular}{lcccccccc}
\hline Predictor & $\mathbf{1}$ & $\mathbf{2}$ & $\mathbf{3}$ & $\mathbf{4}$ & $\mathbf{5}$ & $\mathbf{6}$ & $\mathbf{7}$ & $\mathbf{8}$ \\
\hline 1. Demographic risk & - & -.15 & .07 & .19 & .10 & -.12 & .14 & $.39^{*}$ \\
2. Maternal verbal IQ & & - & .15 & -.03 & -.01 & .05 & .15 & -.06 \\
3. Child gender ${ }^{a}$ & & & - & .07 & .09 & .07 & .19 & .19 \\
4. Maternal withdrawal & & & - & $-.35^{*}$ & -.01 & $.36^{*}$ & $.42^{*}$ \\
5. Child nonverbal IQ & & & & - & .21 & $.50^{* *}$ & .14 \\
6. Child verbal IQ & & & & - & - & .08 & .14 \\
7. Substance use disorder (alcohol, cannabis) & & & & & & & - & $.36^{*}$ \\
8. Substance use disorder (other drugs) & & & & & & & - \\
\hline
\end{tabular}

Note. Strength of association for two continuous variables was indexed by Pearson correlation coefficient; strength of association for one dichotomous and one continuous variable was indexed by eta statistic (nondirectional), with significance assessed by t-test.

$$
\begin{aligned}
& a_{1=\text { female; }} 0=\text { male; } \\
& { }^{*}<.05 ; \\
& { }^{* *}<.01 .
\end{aligned}
$$


Table 2

Logistic Regression Predicting Substance Use Diagnosis (Alcohol/Cannabis) in Young Adulthood ${ }^{a}$

\begin{tabular}{lcccc}
\hline & \multicolumn{2}{c}{ Entry Block } & \multicolumn{2}{c}{ Final Block } \\
Predictor & B entry (SE) & B final (SE) & Wald $\chi^{\mathbf{2}(d f=\mathbf{1})} \quad \mathbf{e}^{\mathbf{B}}$ (Odds Ratio) \\
\hline Block 1 & & & \\
Demographic risk & $.51(.45)$ & $1.32(.93)$ & 2.03 & 3.74 \\
Maternal IQ & $.14(.11)$ & $.21(.14)$ & 2.15 & 1.23 \\
Child gender $b$ & $1.11(.81)$ & $1.62(1.13)$ & 2.07 & 5.06 \\
Block 2 & & & & \\
Maternal withdrawal & $.31(.16)^{*}$ & $.18(.20)$ & .83 & 1.20 \\
Block 3 & & & & \\
Child verbal IQ & $.32(.24)$ & $.32(.24)$ & 1.87 & .480 \\
Child nonverbal IQ & $-.73(.32)^{*}$ & $-.73(.32)^{*}$ & 5.25 & \\
\hline
\end{tabular}

$a_{\text {Note. } 1}$ = Diagnosis, $0=$ No diagnosis;

$b_{1}=$ female, $0=$ male;

*

${ }^{*}<.05$,

$*$ p $<.01$. 
Table 3

Indirect Ef fect of Maternal Withdrawal on a Substance Use Diagnosis (Alcohol/Cannabis) through Child Nonverbal IQ

\begin{tabular}{lccc}
\hline & & Bootstrapping ${ }^{a}$ Percentile 95\% CI \\
\hline Indirect Effects & Point Estimate (SE) & Lower & Upper \\
Child nonverbal IQ & $.18(.23)$ & .0100 & .9267 \\
\hline
\end{tabular}

${ }^{a}$ Note. 1,000 bootstrap samples. 